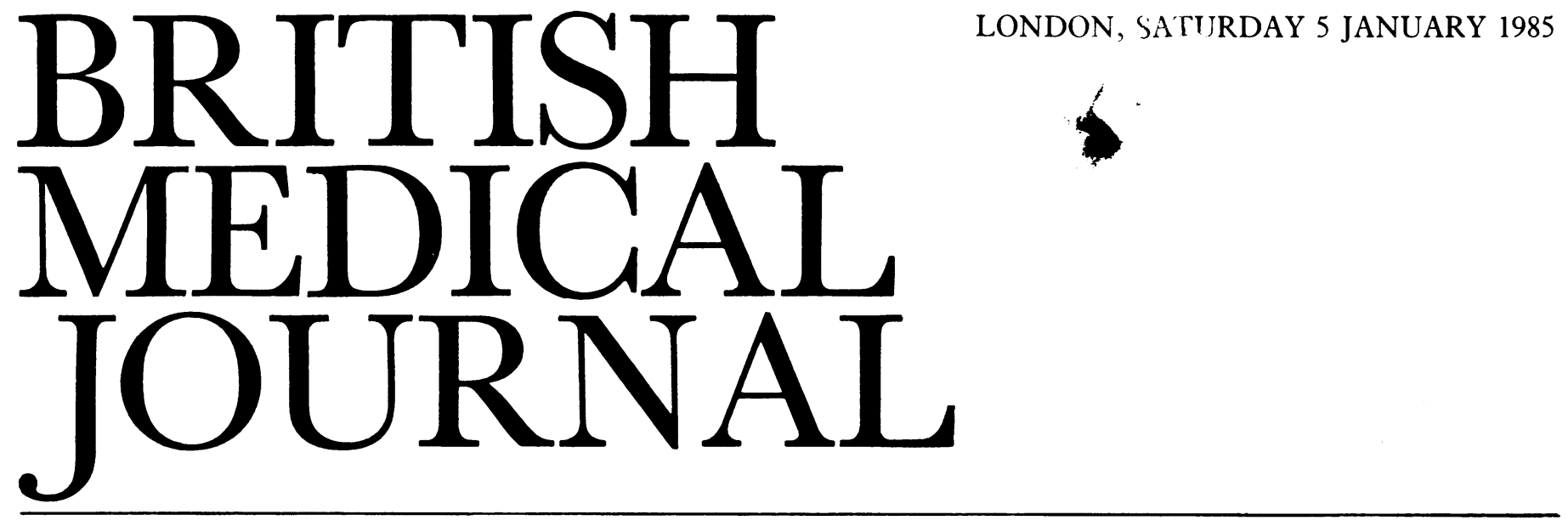

\title{
The politics of alcohol
}

Few things are certain where alcoholism is concerned. Delegates at a recent conference on "Alcohol: Preventing the harm," sponsored by the BMA and the Institute of Alcohol Studies, were left in no doubt, however, by the junior health minister John Patten that the present government had no intention of taking any action to curb alcohol abuse. Society, he said, had as yet no clear cut view, and it was not for government to intervene: individuals must be encouraged to take responsibility for their own health, and the professionals had been given the means, thanks to the generosity of politicians, to combat the dangers of alcoholism.

"The government," declared Derek Rutherford of the Institute of Alcohol Studies, "is more dependent on alcohol than any alcoholic." Taxes and excise duty bring in a massive $£ 4000$ million a year; no wonder successive governments have suppressed reports calling for curbs on availability and realistic price' rises at home and have put pressure on the Council of Europe and the World Health Organisation to modify initiatives that would affect Britain. Alcohol consumption among members of parliament is high_-as it is, for example, among police and doctors (ready availability and the stresses of the job both contribute)-and there is a powerful drinks lobby in parliament. What then must be done to convince society by those of us who believe that alcoholism needs to be tackled now?

One way, as Professor R E Kendell showed the conference, is to provide irrefutable evidence. ${ }^{1}$ In spite of some statistical problems the Ledermann hypothesis or consumption model of alcoholism has stood the test of time: in every country studied increases in per capita consumption of alcohol are paralleled by rises in all indices of alcohol damage. Since consumption has increased dramatically in many parts of the world in the past 30 years it is hardly surprising that experts talk about an epidemic of alcoholism. But the corollary is also true, though examples are now difficult to come by: a fall in consumption, most strikingly apparent in the west during two world wars, is mirrored by a sharp decline, for instance, in deaths from cirrhosis of the liver. It is sometimes argued (especially by the drinks lobby) that increasing the cost of alcohol puts an unfair burden on the innocent social drinker without altering the behaviour of the heavy drinker, but there is plenty of evidence that this is not so, and recent figures from Lothian show a fall in harmful effects among heavy drinkers after a modest price rise. ${ }^{2}$

Every speech at the conference emphasised the importance of fiscal policies in programmes to combat alcoholism. The price of alcohol in Britain is ridiculously low in relation to the cost of living - but with two thirds of the population drinking regularly only a government bent on political suicide would sanction realistic price rises. A graduated increase over the next ten years might be acceptable, however, if people were convinced that it would cut down the harm done at present. In the short term the most effective action would be to reduce availability and to take a close look at production, imports, outlets, and the working (at present largely ineffective) of legal restraints on drinking. The current campaign for less rather than more control orchestrated by the drinks and catering industries has a good deal of public support and does not augur well for measures aimed at restricting alcohol.

Public attitudes are slow to change; complacency and ignorance are widespread. It is extraordinary that a statistic of one million or more "alcoholics" in Britain raises hardly a murmur, yet panic ensues when the number of drug addicts reaches 50000 . Health educationalists (with a budget of $£ 1-2$ million as against the drinks industry's $£ 100$ million for advertising) admit that national campaigns to discourage excessive drinking have mostly been ineffective, and their strategy is currently under review. Derek Lambert of the Health Education Council said that programmes needed to be designed to stimulate public debate, to alter the climate of opinion, and to challenge prevailing mythologies. They should not be produced in isolation but linked to ideas about healthy living. A second component was the provision of material for professionals-doctors, teachers, police, and managers. An important aspect of ten ignored was evaluation, which should be mandatory in all projects concerned with alcoholism; it had been built in to the campaign to be launched in the south west of England next year.

Other measures which could help reduce the harm were considered by Professor Sir John Crofton: efforts to stop mixing work and drinking, improved employee health services, training at all levels, encouragement of local initiatives, monitoring of drinking habits in different communities, and better coordination of advice and services. (No fewer than 16 government departments are concerned with various aspects of alcohol, yet the British are unique in Europe in not having a central coordinating committee.) Health workers might also do more to enlist the help of the media: Esther Rantzen's That's Family Life programme on $\mathrm{BBC} \mathrm{TV}$, for example, reached 9 million people and the excellent Which? report was sent to 700000 subscribers. Doctors could give a lead by publicly committing themselves 
to safe levels of alcohol; as with cigarette smoking, such a move might persuade others to follow suit, especially if it was shown to reduce the high death rate, from cirrhosis, among doctors.

But can we afford to wait another 20 years? Professor Alan Maynard put the minimum social cost of alcoholism in 1983 from losses to industry, demands on health services, police, and judiciary, damage to property, etc at $£ 1600$ million. After remaining steady for the past few years alcohol consumption is beginning to rise again, and we can confidently expect more casualties. Controls on drinking have had to be imposed in this country at some time in each of the past three centuries: the evidence suggests that the government may soon be forced to heed the lessons of history.

Alex Paton

Postgraduate Dean

North East Thames Region,

London WCIN 3EJ

1 Kendell RE. Alcoholism: a medical or a political problem? Br Med $\mathcal{f}$ 1978;i:367-71.

2 Kendell RE, de Roumanie M, Ritson EB. Effect of economic changes on Scottish drinking habits 1978-82. Br f Addict 1983;78:365-79.

\section{Some rare medical complications of pregnancy}

A pregnant woman with renal failure, a raised serum bilirubin concentration, and a bleeding diathesis presents a clinical picture which, despite passing reference in editorials, has not been sufficiently discussed. ${ }^{1}$ The patient might have severe pre-eclampsia, acute fatty liver of pregnancy, haemolytic-uraemic syndrome, or thrombotic thrombocytopenic purpura, all fairly rare conditions. ${ }^{2-4}$ Because the obstetrician may manage the patient alone or may consult a gastroenterologist, haematologist, nephrologist, or neurologist few clinicians have much experience of the syndrome or of the diagnostic possibilities outside the scope of their own specialty. At least one condition (acute fatty liver of pregnancy) is associated with a perinatal mortality of $70 \%$ and maternal mortality of $80 \%$, so that the diagnosis and management of patients presenting in this way deserve further attention. ${ }^{5}$

About $3 \%$ of pregnancies are complicated by proteinuric pre-eclampsia. Perhaps a tenth of these patients will have impaired liver function, renal failure, and a bleeding diathesis, ${ }^{6}$ making the overall incidence of this very severe form of pre-eclampsia about three per 1000 deliveries. Sometimes the patient may have heavy proteinurea and gross oedema, as in the nephrotic syndrome.

Acute fatty liver has been thought to be a very rare complication of pregnancy with an incidence below one in 10000 deliveries. ${ }^{7}$ With greater awareness of the condition, however, milder forms may be recognised more frequently in the future. ${ }^{8}$ The patient usually presents in late pregnancy with severe abdominal pain and vomiting. She rapidly becomes jaundiced, develops disseminated intravascular coagulation, and may die of haemorrhage, liver failure, or hypoglycaemia. ${ }^{9}$ She may have mild hypertension and proteinuria with evidence of renal failure. As in severe pre-eclampsia, multiple pregnancy is a risk factor; however, primigravidas are not necessarily more commonly affected than multigravidas and the condition is much more common with a male fetus. ${ }^{78}$ Histological examination of the liver shows the deposition of fatty droplets, ${ }^{10}{ }^{11}$ in contrast to the fibrinoid necrosis and petechial haemorrhage in the liver in pre-eclamptic toxaemia. ${ }^{12}$

The spectrum of illness ranging from the haemolyticuraemic syndrome to thrombotic thrombocytopenic purpura occurs in non-pregnant women but appears to be relatively common in pregnancy. Patients with acute fatty liver of pregnancy may die within two days of presentation; this is uncommon with haemolytic-uraemic syndrome or thrombotic thrombocytopenic purpura, though these too have a high mortality in pregnancy. One review found only 14 survivors of thrombotic thrombocytopenic purpura in pregnancy in all the published accounts, ${ }^{13}$ and May et al had only three survivors among their patients. ${ }^{14}$ This spectrum is associated with microhaemangiopathic haemolytic anaemia and thrombocytopenia. In thrombotic thrombocytopenic purpura neurological abnormalities dominate the presentation. The patient may have epileptic fits mimicking eclampsia and she often has a curious personality change, becoming detached and peculiar in manner to a degree that becomes apparent only if and when she recovers her premorbid personality. The haemolytic-uraemic syndrome usually, though not invariably, occurs post partum, ${ }^{15}$ in association with renal failure ${ }^{16}$; the outcome is usually chronic renal failure. ${ }^{17} 18$

All these conditions are of unknown cause. Acute fatty liver of pregnancy has been associated with treatment with parenteral tetracycline in earlier series, but this is now very uncommon. ${ }^{19}$ The histological similarities with Reye's syndrome and other microvesicular fat diseases suggest that there may be abnormalities of the mitochondrial enzymes in Krebs's cycle in acute fatty liver, perhaps associated with some toxin or viral agent, but why should the pregnant woman be particularly susceptible to such a toxin?

Thrombotic thrombocytopenic purpura and haemolyticuraemic syndrome share so many features that they should be considered as one condition. Children with the haemolytic-uraemic syndrome may have a prodromal illness with upper respiratory or gastrointestinal features, and the condition has therefore been thought to be a hypersensitivity state. ${ }^{17}$ Escherichia coli toxin has also been implicated. ${ }^{20}$ In thrombotic thrombocytopenic purpura deficiency of a plasma factor such as prostacyclin has been thought to be important in the pathogenesis but whether the deficiency is a cause or effect is still not clear. ${ }^{21} 22$

How can we differentiate these conditions, and is it important to do so? The histological appearances in acute fatty liver of pregnancy and severe pre-eclampsia have already been mentioned. Biopsy specimens from the gums may show subendothelial and intramural hyaline deposits in blood vessels in thrombotic thrombocytopenic purpura or the haemolytic-uraemic syndrome. ${ }^{23}$ The clinical picture is usually too acute to await the results of a biopsy, however, and liver biopsy is contraindicated in patients with severe disseminated intravascular coagulation, though centres with sufficient expertise might consider the transjugular approach. ${ }^{7}$ Possibly computed tomography or ultrasound scanning will allow the liver fat content to be estimated and thus lead to a diagnosis of acute fatty liver of pregnancy, but this has yet to be shown. ${ }^{7}$

In patients who have features of both pre-eclamptic toxaemia and acute fatty liver of pregnancy the differential diagnosis has to be based on the relative severity of the presenting features. Thus patients who present primarily with severe hypertension, gross oedema, and albuminuria are more likely to have pre-eclamptic toxaemia, and those 